\title{
Neural Correlates of Aggression among Individuals from Low and High Socioeconomic Status: An ERP Study
}

\author{
Yizhu Wang ${ }^{1,2}$, Yufang Zhao ${ }^{1}$, Jiang Qiu ${ }^{1,3}$, Oscar Ybarra ${ }^{4}$, Lu Liu ${ }^{1} \&$ Yuqing Huang ${ }^{1}$ \\ ${ }^{1}$ School of psychology, Southwest University, Chongqing, China \\ ${ }^{2}$ Chongqing Industry Polytechnic College, Chongqing, China \\ ${ }^{3}$ Key Laboratory of Personality and Cognition, Ministry of Education, Southwest University, Chongqing, China \\ ${ }^{4}$ Department of Psychology, University of Michigan, Ann Arbor, USA \\ Correspondence: Yufang Zhao, School of psychology, Southwest University, Beibei, Chongqing, 400715, China. \\ Tel: 86-23-6825-4761. E-mail: wyz.1211@163.com
}

$\begin{array}{lc}\text { Received: August 28, } 2012 & \text { Accepted: September 25, } 2012 \quad \text { Online Published: November 12, } 2012 \\ \text { doi:10.5539/ijps.v4n4p37 } & \text { URL: http://dx.doi.org/10.5539/ijps.v4n4p37 }\end{array}$

This study was funded by the Fundamental Research Funds for the Central UniversitiesSWU1209321, and National Natural Science Foundation of China (31000470).

\begin{abstract}
Event-related brain potentials were recorded to investigate electrophysiological correlates of aggression in high and low socioeconomic status (SES) participants who responded to violent and nonviolent images by using a choice reaction time paradigm. ERP data showed that violent images elicited a smaller N2 deflection than did nonviolent images in both high and low SES groups, but there was no difference in N2 amplitudes to aggressive and non-aggressive information as a function of SES. Notably, the latency of N2 in the low SES group was longer than that of the high SES group, suggesting slowness by the low SES group in deploying control responses. In addition, the low SES group exhibited significantly smaller P3 amplitudes to violent images, suggesting a reduction in brain activity known to reflect activation of the aversive motivational system, and this findings link this brain activity to aggressive behavior. As a whole the present findings show that participants low in SES seem to display similar psychophysiological responses to individuals high in aggression.
\end{abstract}

Keywords: socioeconomic status (SES), aggression, group identification, N2, P3

\section{Introduction}

Aggression defined as the expression of angry verbal or motor behavior directed toward people or objects. It is common in people and non-human animals, and not only includes aggressive behavior but also refers to a set of psychological and emotional responses (Stewart et al., 2010; Krämer, Büttner, \& Münte, 2008). Although it is common for people to show and experience aggression, for example, as a result of frustrating life experiences (Miller, 1941), recurring exposure to circumstances that trigger aggression (e.g., violent imagery, interpersonal aggression, conflict) can desensitize individuals to it. As a consequence, prolonged exposure to certain life circumstances can make people less cognitively and emotionally affected by violence and aggressive events and information, which can facilitate future aggressive responding by precluding the overriding of emerging, aggressive reactions (Engelhardt, Bartholow, Kerr, \& Bushman, 2011). This proposal, which captures the desensitization hypothesis, has been supported in studies that examined individual differences in exposure to violent content (e.g., people who play violent video games) (Bartholow, Bushman, \& Sestir, 2006). In the present study we test the desensitization hypothesis by investigating the responses of individuals who, due to their place in the social structure in terms of socioeconomic status (SES), may be prone to different levels of aggressive responses. Further, to better gauge the relationship between SES and aggressive responding, we use an ERP methodology to examine at the electrophysiological level the responses of low and high SES groups to violent and non-violent imagery.

Socioeconomic status (SES) is an aggregate concept defined according to one's level of resources or prestige in relation to others (Gallo \& Matthews, 2003; Lynch \& Kaplan, 2000). SES is measured by income and occupation 
or educational attainment (Gallo \& Matthews, 2003; Henry, 2009; Kraus, Piff, \& Keltner, 2009). It is argued that due to status discrepancies that arise in social hierarchies, those at the bottom of the hierarchy attain fewer resources and prestige and become stigmatized (Henry, 2009). They are considered to face long-term stressors due to status inequalities (Marmot, Bobak, \& Smith, 1995). Stigmatized individuals have a sense that others do not value them, and the experience of stigma is characterized by feelings of not being socially accepted by others (Crocker \& Major, 1989). Because being devalued and not accepted has been shown to lead to aggressive responses on the part of the rejected individuals (Twenge, Baumeister, Tice, \& Stucke, 2001), it follows that a relationship between SES and aggression should hold, and there are some indications of this as we will review presently.

The extant literature has documented some relationships between SES and behavioral indicators of hostility / aggression (Gallo \& Matthews, 2003; Àslund, Starrin, Leppert, \& Nilsson, 2009; Ranchor, Bouma, \& Sanderman, 1996; Barefoot et al., 1991; Scherwitz, Perkins, Chesney, \& Hughes, 1991). In one study, for example, McFarlin, Fals-Stewart, Major, \& Justice, (2001) found a significant negative correlation between income and verbal or physical aggression and Dodge, Pettit, \& Bates (1994) found that low SES is associated with aggressive behavioral problems. Other studies examining the association between SES (including education, income and occupation) and hostility suggest a linear, inverse relationship (Barefoot et al., 1991; Lynch, Kaplan, \& Salonen, 1997). Thus, different studies suggest that low SES - whether studied in adults or children -is associated with expressing attitudes of aggression and hostility toward others.

In terms of methodology, the relationship between SES and aggressive responses has been demonstrated using methods such as questionnaires or behavior experiments (Henry, 2009; Kraus et al., 2009; Aneshensel \& Sucoff, 1996). Despite their usefulness, these studies have limitations as they depend on overt responses such as response times or explicit judgments, all of which can collapse over many stages of processing (Barefoot et al., 1991; Scherwitz et al., 1991; McFarlin et al., 2001; Dodge et al., 1994; Lynch et al., 1997; Aneshensel \& Sucoff, 1996). As is widely understood, ERPs provide good temporal resolution and thus allow for a more precise examination of time course and distinctions to be made among different stages of processing (Chen et al., 2008). However, no studies have addressed this relationship in an event-related potentials study. Doing so may allow researchers to better pinpoint some of the psychological processes that mediate the effect of SES on aggressive tendencies, as ERP has been used in aggression research.

In the present study we sought to examine how people low on SES - compared to those high SES group — differ in their responses to violent images using a high temporal resolution ERP technique. Theoretically, aggression-related responding should be reflected in the amplitudes and latencies of the N2 and P3 components of the ERP. The important elements in aggressive responding are the cognitive processes related to impulse and emotion control, as aggression if elicited without little cognitive intervention represents a behavior beyond the bounds of control. Previous research indicates that N2 reflects the suppression of behavioral responses during impulse control processes (Dong, Yang, Hu, \& Jiang, 2009; Stewart et al., 2010). Other researchers have found longer N2 latencies to conflicting information, suggesting slowed responses in detecting response conflicts (Yuan, He, Zhang, Chen, \& Li, 2008). In their review, Perdeci et al., (2010) suggested that the N2 component has been used in many studies investigating the neurophysiological causes of aggressive behavior. Some research has found that aggressive individuals displayed larger N2 amplitude to negative stimuli, suggesting that individuals with high levels of aggression need to exert attentional effort to override their focus on negative (likely anger-related) information (Stewart et al., 2010). A clear correlation between aggressive behavior and the larger N2 amplitude for the high trait aggressive group, but a similar relation was absent in the low trait aggressive group. And researchers also observed enhanced N2 amplitude in high compared to low impulsive-aggressive condition (Krämer, Büttner, Roth, \& Münte, 2008).

According to the present analysis, if low SES - due to the factors discussed above - can serve as a risk factor for desensitizing individuals to aggression and violence, then it should be expected that low SES group should be more psychologically blunted to information — such as violent imagery - that poses or triggers a psychological conflict (i.e., between their automatic response to the information and what is socially desirable behavior). Consequently, they should display longer N2 latencies and larger N2 amplitudes to information with aggressive content than high SES participants.

Related to the above discussion on detecting response conflicts, another factor that should matter to aggressive responding is the availability or application of cognitive resources. In terms of the P3 component, dual-task experiments have suggested that $\mathrm{P} 3$ amplitude and psychological resources have a positive relationship (Perdeci et al., 2010). With regard to aggressive behavior, the P3 amplitude of ERP appears to be a useful indicator as well (Yuan et al., 2008; Perdeci et al., 2010). Bond and Surguy (2000) suggested that smaller P3 amplitude could 
be an indicator of violent behavior and aggressiveness. Previous studies examining aggressive behavior have consistently shown that P3 amplitude is significantly lower in aggressive compared to non-aggressive populations (Barratt, Stanford, Kent, \& Felthous, 1997; Gerstle, Mathias, \& Stanford, 1998), and lower P3 amplitude has been suggested to reflect the involvement of fewer neural resources and engagement at this stage of processing. The P3 amplitude of impulsive-aggressive subjects has also been shown to be significantly lower than that of non-aggressive subjects (Gerstle et al., 1998; Duncan et al., 1994). Mathias and Stanford (1999) found, for example, that impulsive-aggressive individuals showed reduced P3 amplitudes to rare stimuli compared to non-aggressive subjects. Even more relevant to this research, Bartholow et al., (2006) observed that P3 amplitude to violent images was smaller in aggressive players than non-aggressive players, and that this effect did not generalize to other negative images. Thus, based on a desensitization perspective, if low compared to high SES group is associated with more aggressive responses, it is expected that low SES group will deploy fewer cognitive resources in response to aggressive information, which should result in smaller P3 amplitudes.

In this study we focused on people who identify with their SES, meaning the degree to which they consider the groups they are part of to be an important element of the self (Tajfel \& Turner, 1979). Group identification matters because even though a person can be categorized on objective criteria as being low or high in SES, they may not necessarily judge that categorization as capturing important elements of who they are. Thus, a person low in SES who does not identify with their SES may not necessarily perceive threats from those high in SES or experience life events as stigmatizing, which should limit the creation and activation of aggressive related responses. Research that supports the importance of group identification has shown, for example, that people who identify highly with their group membership (e.g., ethnic minorities who identify with their ethnicity) are more likely to conform to group norms (Weenig, van der Salm, \& Wilke, 2004) and contrast how they define themselves from how members of out-groups define themselves (Hall and Crisp, 2008). High group identifiers have also been shown to express more solidarity with in-group members and to stress in-group homogeneity (i.e., we are all similar in this group) and loyalty (Doosje, Spears, \& Ellemers, 2002). Thus, in order to better pinpoint the implications SES has for aggressive responses, we selected for the present study participants who identified highly with having high or low SES.

To assess differences in neurological responses as a function of SES, in the present study we used a choice reaction time paradigm. This should engender better understanding of the relationship between SES and aggressive responding because this paradigm has been applied in several electrophysiological studies to investigate aggression, particularly, the responses to violent and non-violent imagery. We predicted that compared with groups high in SES, low SES group would display longer N2 latencies and larger N2 amplitudes while displaying smaller $\mathrm{P} 3$ amplitudes.

\section{Method}

\subsection{Participants}

34 undergraduates (19 women, 15 men; 17 high SES, 17 low SES; age range 19-23 years) from Southwest University in China were paid to participate in the study. All participants were healthy, right-handed, and had normal or corrected-to-normal vision and no current or history of neurological or psychiatric disorder, as indicated on the informed consent form.

\subsection{Measures}

\subsubsection{Socioeconomic Status}

SES of participants was determined by their responses to questions concerning family income, parents' educational attainment, and parents' occupations. We used parent instead of student information because college students typically are not financially independent and will therefore have a status based on their upbringing in their family household (Henry, 2009; Àslund et al., 2009). Participants responded to "What do you estimate your parents' combined monthly income to be?" with a choice of 7 options ranging from $1=$ under $¥ 600$, to $7=$ $¥ 12000$ or over. The options were scaled in increments of $¥ 1200$ (e.g., Ұ600- ¥1799. ¥1800- ¥2999) up to $¥ 2999$, beyond which the scaling changed to increments of $¥ 3000$. The median response was $4=¥ 3000$ $¥ 6000$. Participants then responded to "What's your parents' education?" selecting among 7 contiguous categories ranging from $1=$ little or no literacy, $2=$ primary school student, $3=$ middle school student, $4=$ high school student, $5=$ junior college student, $6=$ undergraduate student, $7=$ postgraduate student. Finally, participants responded to "What's your parents' occupation?" ranging from $1=$ unemployed/migrant worker/temporary worker, $2=$ manual worker, $3=$ skilled worker, $4=$ office worker, $5=$ common managerial/technical personnel, $6=$ middle-level managerial/technical personnel, $7=$ high-level managerial/technical personnel. High SES was ascribed to the participants whose total scores ranged from 17 to 
21. Participants were categorized as low SES if their total scores ranged from 3 to 8 (Henry, 2009; Kraus et al., 2009).

\subsubsection{SES Group Identification}

For assessing the degree to which participants identified with their SES, participants were first asked to report on what they believed their SES group to be using the following options: $1=$ I believe my family is very wealthy, $2=$ I believe my family is wealthy, $3=\mathrm{I}$ believe my family is middle income, $4=\mathrm{I}$ believe my family is poor, $5=\mathrm{I}$ believe my family is very poor. Following this, participants responded to four questions to assess group identification (Henry, 2009; Doosje et al., 2002; Smith, Seger, \& Mackie, 2007). Using 7-point scales anchored by "do not agree at all" (1), and "agree completely" (7), participants responded to statements such as "I identify strongly with other high/low socioeconomic status members," "Being a high/low socioeconomic status member is an important part of who I am," "I feel strong ties with other high/low socioeconomic status members," and "I feel a sense of solidarity with other high/low socioeconomic status members." The four items formed a reliable scale (Cronbach $\alpha=.73$ ). In order to choose high and low SES members who identified with their SES, we used $+1 \mathrm{SD}$ as the cutoff point. Only participants who met this criterion during this part of the study were allowed to complete the main, ERP aspect of the study.

\subsubsection{Stimuli}

The choice reaction time paradigm consisted of 2 blocks of 60 trials, and each block included 30 violent images and 30 nonviolent images. To validate the valence and arousal potential of the images, we tested the images as done by other researchers (Carretie, Mercado, Tapia, \& Hinojosa, 2001; Johnson, 1993). Pilot test participants rated the images on valence using scales ranging from 1 (completely unhappy) to 9 (completely happy), and on arousal using scales ranging from 1 (completely calm) to 9 (completely aroused) (Bartholow et al., 2006; Lang, Bradley, \& Cuthbert, 2001). The means and standard deviations for these ratings are presented in Table 1.

Table 1. Average valence and arousal are rating for the image in this study

\begin{tabular}{lll}
\hline Image type & Valence ratings & Arousal ratings \\
\hline Violent & $1.82(0.64)$ & $6.65(1.06)$ \\
Nonviolent & $7.24(0.83)$ & $4.41(2.06)$ \\
\hline
\end{tabular}

Note. All images include 30 violent images and 30 nonviolent images.

As can be seen in Table 1, valence and arousal ratings for violent and nonviolent images were significantly different $[\mathrm{t}(16)=18.17, \mathrm{p}<0.001 ; \mathrm{t}(16)=4.31, \mathrm{p}=0.001]$.

Examples of the violent images included a man holding a gun to another man's head, and a man striking another man with his fist. Examples of nonviolent images included two men standing talking or doing something on their own. The violent images and nonviolent images were randomized for each subject by the computer program. All the pictures were identical in size and resolution $(15 \mathrm{~cm} \times 10 \mathrm{~cm}, 100$ pixels per inch). In addition, the luminance level of the pictures used was tested prior to the experiment and matched across the two valence conditions. The contrast of the monitor was set to a constant value across subjects (Li, Yuan, \& Lin, 2008).

\subsection{Behavioral Procedures}

In a quiet room all participants were seated at approximately $150 \mathrm{~cm}$ from a computer screen with the horizontal and vertical visual angles below $6^{\circ}$. Prior to the experiment, participants were told that the purpose of the study was to investigate "the effects of picture viewing on reaction times." The procedure began with a white fixation point that appeared between 300 and $600 \mathrm{~ms}$ in the center of the computer screen. This was followed by a blank screen whose duration was randomly varied between 1000 and $1500 \mathrm{~ms}$. Then the picture stimulus followed, and its presentation was terminated by pressing a key or automatically after $1500 \mathrm{~ms}$ if no key press was made. Each subject was instructed to press the "F" key on the keyboard with their left index finger as accurately and quickly as possible if the images were thought to be violent and to press the " $\mathrm{J}$ " key with their right index finger if the images were thought to be nonviolent (Li et al., 2008; Qiu et al., 2007).

\subsection{ERP Recording and Analysis}

Brain electrical activity was recorded from 64 scalp sites using tin electrodes mounted in an elastic cap (Brain Products GmbH, Stockdorfer, Munich, Germany), with references on the left and right mastoids. A vertical 
electrooculogram (EOG) was recorded with electrodes placed above and below the left eye. The inter-electrode impedance was maintained below $5 \mathrm{k} \Omega$. The electroencephalogram (EEG) and EOG were amplified using a $0.05-100 \mathrm{~Hz}$ bandpass and continuously sampled at a $500 \mathrm{~Hz}$ channel for off-line analysis. Eye movement artifacts (blinks and eye movements) were rejected offline. Trials with EOG artifacts (mean EOG voltage exceeding $\pm 80 \mu \mathrm{V}$ ) and those contaminated with artifacts due to amplifier clipping, bursts of electromyographic activity, or peak-to-peak deflection exceeding $\pm 80 \mu \mathrm{V}$, were excluded from averaging (Qiu et al., 2007).

The ERP waveforms were time locked to the onset of stimuli and the averaged epoch was $700 \mathrm{~ms}$, including a 100-ms pre-answer baseline. Only segments with correct judgments were used in the ERP analysis. On the basis of the grand average of the ERP (see Figure 1), prominent N2 and P3 components were elicited as a function of SES and image type (nonviolent images by high SES participants (NH), nonviolent images by low SES participants (NL), violent images by high SES participants (VH), and violent images by low SES participants $(\mathrm{VL})$ ). Thus, the present study measured and analyzed the latencies (from stimulus onset to the peak of each component) and amplitudes (baseline to peak) of $\mathrm{N} 2$ and $\mathrm{P} 3$ components. The following 10 electrode sites [FC4, $\mathrm{FC} 3, \mathrm{FC} 1, \mathrm{FC} 2, \mathrm{FCz}$ (frontal-central sites), Cz, C1, C2, C3, C4 (central sites)] were selected for statistical analysis of the $\mathrm{N} 2$ component (180-270ms), and $\mathrm{P} 3(300-390 \mathrm{~ms})$ was analyzed at the 4 electrode sites $(\mathrm{FCz}, \mathrm{Cz}$, $\mathrm{C} 1, \mathrm{C} 2$ ) (Li et al., 2008). Electrode sites and scoring windows for N2 and P3 were chosen by examining grand-average waveforms and individual participant data and consulting aggression ERP literature measuring these components (e.g., Gerstle et al., 1998; Mathias \& Stanford, 1999; Houston \& Stanford, 2001) A mixed analysis of variance (ANOVA) on the amplitude and latency of each component was conducted, with image type (two levels: violent, nonviolent) and electrode sites as within-subjects factors, and SES as the between-subjects factor (e.g., Li et al., 2008). For all analyses, P values were corrected for deviations according to the Greenhouse-Geisser method.

\section{Results}

\subsection{Behavioral Performance}

There were no significant differences between men and women in accuracy rates and reaction times. The accuracy rates for categorizing the images as a function of content and participant SES showed no differences (all effects non-significant). The means for responses to $\mathrm{NH}, \mathrm{NL}, \mathrm{VH}$, and $\mathrm{VL}$ were $95.2 \pm 2.9,91.7 \pm 6.3$, $93.4 \pm 12.9$, and $96.4 \pm 3.3$, respectively. The reaction times for $\mathrm{NH}, \mathrm{NL}, \mathrm{VH}$, and VL were $722 \pm 167 \mathrm{~ms}, 662 \pm 127$ $\mathrm{ms}, 648 \pm 194 \mathrm{~ms}$, and $585 \pm 84 \mathrm{~ms}$.

For both high SES and low SES participants, mean reaction times to the nonviolent images were longer than reaction times to the violent images (high SES: $722 \pm 167 \mathrm{~ms}$ vs. $648 \pm 194 \mathrm{~ms})$; low SES: (662 $\pm 127 \mathrm{~ms}$ vs. $585 \pm 84$ $\mathrm{ms}), \mathrm{F}(1,32)=13.18, \mathrm{p}=0.001$. Thus, overall participants responded more quickly to images with aggression-related content than neutral ones, which is consistent with other research in social perception (Ybarra, Chan, \& Park, 2001). The main effect of SES and the interaction of the two factors were not reliable.

\subsection{ERP Analysis}

In terms of gender, there were no reliable differences between men and women with respect to all of the ERP components. The $\mathrm{N} 2$ component between 180 and 270 ms was measured at FC4, FC3, FC1, FC2, FCz, Cz, C1, $\mathrm{C} 2, \mathrm{C} 3, \mathrm{C} 4$. The results indicated that the nonviolent images elicited a more negative ERP amplitude deflection at $200 \mathrm{~ms}$ than the violent images $[\mathrm{F}(1,32)=9.9, \mathrm{p}<0.01]$.

In terms of the N2 component latency, the results showed a significant main effect for SES $[\mathrm{F}(1,32)=38.69$, $\mathrm{p}<0.001]$, and also a significant interaction between electrode sites and $\operatorname{SES}[\mathrm{F}(9,288)=2.35, \mathrm{p}<0.05]$. The main effect indicates that the latency of the N2 expressed by participants of low SES peaked later than those of higher SES (Figure 1).

The P3 component between 300 and 390 ms was measured at $\mathrm{FCz}, \mathrm{Cz}, \mathrm{C} 1, \mathrm{C} 2$. The repeated measures ANOVA on P3 amplitudes showed significant main effects of image type $[\mathrm{F}(1,32)=62.87, \mathrm{p}<0.001]$, and also a significant SES by image type interaction $[\mathrm{F}(1,32)=5.93, \mathrm{p}<0.05]$ and a significant electrode sites by image type interaction $[\mathrm{F}(3,96)=7.20, \mathrm{p}=0.001]$ (Figure 1). Simple effects analyses of the interaction between SES and image type demonstrated a significant effect for SES. To the nonviolent images, members of the different SES groups showed no differences. But to the violent images, P3 amplitudes were smaller for low SES members than for high SES members $[\mathrm{F}(1,32)=4.18, \mathrm{p}<0.05]$. 

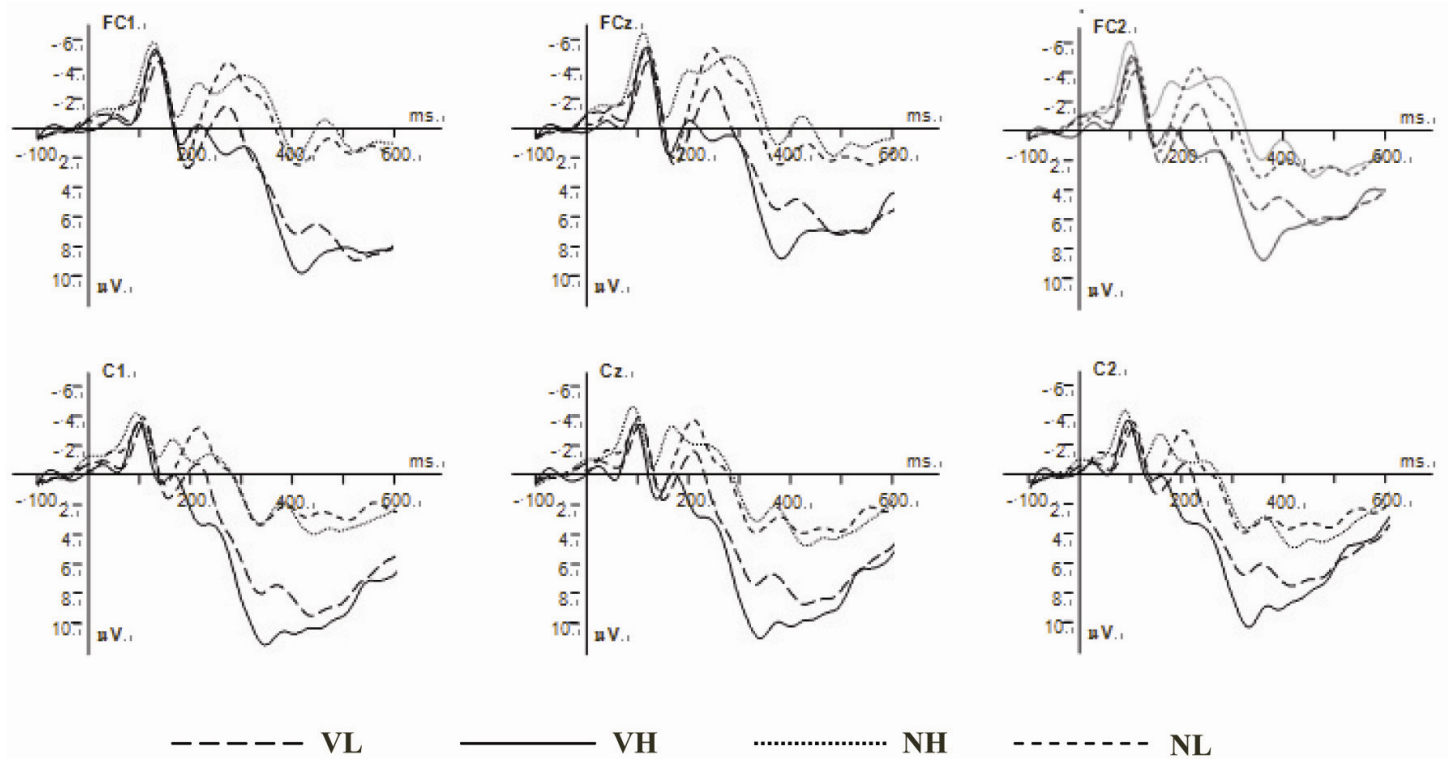

VH

NH

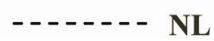

Figure 1. The grand average ERP for NH (nonviolent images by high SES participants), NL (nonviolent images by low SES participants), VH (violent images by high SES participants) and VL (violent images by low SES participants) conditions at the frontal-central $(\mathrm{FC} 1, \mathrm{FCz}, \mathrm{FC} 2)$ and central $(\mathrm{C} 1, \mathrm{Cz}, \mathrm{C} 2)$ electrode sites

\section{Discussion}

In the present study, we used a choice reaction time paradigm to examine the electrophysiological correlates of aggression in high and low SES groups. The results indicated that the N2 component of low SES group peaked later than that of group higher in SES. Low SES group also demonstrated reduced P3 amplitude in response to the violent images compared to high SES group. These results support our hypotheses that the low SES group would display similar psychophysiological responses to the individuals high in aggression and low impulse control.

Previous researchers have proposed a desensitization theory, which puts forth the idea that desensitization can diminish psychological or emotional responses to a stimulus after repeated exposure to it (Wolpe, 1982). Bartholow et al., (2006) found that participants with a history of watching violent media were less sensitive and less likely to be affected when presented with violent stimuli. Applied to the present results dealing with SES, the findings suggest that low SES compared to high SES group may experience greater desensitization, potentially owing to factors such as low SES group enduring more stigmatizing experiences and conflict due to their life circumstances, such as mistreatment by others and greater struggles to attain resources and opportunities for advancement (Bartholow et al., 2006). The cumulative and prolonged experiences with having low status, resources, and opportunities by low SES group may translate to a reduced psychological and emotional responsiveness to aggressive and violence-related triggers and even potentially a relative proneness to aggressiveness-related motivational states (Engelhardt et al., 2011; Twenge et al., 2001).

The present study showed that violent images elicited a smaller N2 deflection than did nonviolent images. The results contrary to our hypotheses, there was no difference in N2 amplitudes to aggressive and non-aggressive information as a function of SES. The results are similar to Perdeci et al., (2010) who observed that there was no difference in N2 amplitude between impulsive aggressive and control group. These findings suggest that all participants may be less able to deploy cognitive resources to impulse control responses to the aggressive information. Distinct interpretations of N2 amplitude effects in the literature suggest several avenues for further research. For the N2 latency we observed a significant main effect of SES regardless of image type. Both violent and non-violent images evoked a longer N2 latency in low SES compared to high SES group. As described above, because the experience of low SES group through various factors may lead to a form of desensitization, it follows that they displayed longer N2 latencies than high SES group to the aggressive information and slowed responses in detecting response conflicts (Twenge et al., 2001; Yuan et al., 2008).

As predicted, the present study found reduced P3 amplitude for the low SES group compared to the high SES group in response to violent images. P3 amplitudes to nonviolent images did not differ by SES status. Related results were reported by Perdeci et al., (2010) who observed that P3 amplitude was significantly smaller in 
aggressive individuals compared to controls. Different findings from the literature suggest that reduced P3 amplitude could be an indicator of violent behavior and aggression (Bond \& Surguy, 2000; Mathias \& Stanford, 1999). The present findings suggest similar aggression responses in participants who are low in SES. In terms of desensitization, it may be that the life circumstances of low SES make them less responsive to violent stimuli and less likely to engage in cognitive engagement, as reflected in the smaller P3 amplitudes (Bartholow et al., 2006; Bond \& Surguy, 2000; Gerstle et al., 1998). The decreases in P3 amplitude to violent images should be associated with increases in aggression, implying a reduction in brain activity known to reflect activation of the aversive motivational system, and this findings link this brain activity to aggressive behavior (Engelhardt et al., 2011).

Overall, the neurophysiological responses of low SES group in response to violent images are generally consistent with prior research and theory dealing with individuals who are high in aggressive tendencies or who may be at risk for displaying such behaviors (i.e., high impulsives). The reason for this may owe to status inequities, which is a likely outcome of how most social systems are organized (i.e., hierarchy) (Henry, 2009).

People of low SES - due to the stigma they endure as well as reduced access to resources and opportunities - may end up manifesting more aggressive responses and behavior, especially toward high SES group, to try to protect their sense of social value and self-worth (Gilligan, 1996). At the same time, because of stigma, low SES group may be more likely to be the targets of disrespect and bad treatment from others (Twenge et al., 2001). Together, such processes may lead to greater desensitization to aggression by those low in SES, which may have the effect of reducing inhibitions against behaving aggressively.

In the present research we explicitly focused on persons who identified with their SES. High identifiers may be more apt to think of themselves in terms of their SES, and for low SES this means being aware of their status and how others stigmatize them, which may make more salient for them the perception of conflict and aggression involved in social events and interactions (Twenge et al., 2001). Participants who do not identify with their group should be less likely to think of themselves in terms of their SES or to view others' treatment toward them as a reflection of the group they belong to (Crocker \& Major, 1989). An important question for future research on SES and aggression should examine the conditions that lead some individuals to identify with their groups more than others.

Two important limitations of the current findings deserve mention. First, although our hypotheses have been supported using ERPs, the relationship between these ERP components and aggressive behavior outside the lab is unknown. Second, some researchers have indicated that social class comprises both an individual's material resources and an individual's perceived rank within the social hierarchy (Kraus et al., 2009). In the present study the criteria for categorizing individuals into different SES groups were based on objective measures but not subjective SES indicators (e.g., assessing social class rank relative to other members of the same university, community or country) (Kraus et al., 2009; Goodman et al., 2001). Thus, it will be important in future research to examine aggressive behavior in the lab and also take into account other subjective aspects of SES to more fully understand how SES relates to aggressive tendencies and behavior.

\section{References}

Aneshensel, C. S., \& Sucoff, C. A. (1996). The neighborhood context of adolescent mental health. Journal of Health and Social Behavior, 37, 293-310.

Àslund, C., Starrin, B., Leppert, J., \& Nilsson, K. W. (2009). Social status and shaming experiences related to adolescent overt aggression at school. Aggressive Behavior, 35, 1-13. http://dx.doi.org/10.1002/ab.20286

Barefoot, J. C., Peterson, B. L., Dahlstrom, W. G., Siegler, I. C., Anderson, N. B., \& Williams, R. B. Jr. (1991). Hostility patterns and health implications: Correlates of Cook-Medley Hostility Scale scores in a national survey. Health Psychology, 10, 18-24.

Barratt, E. S., Stanford, M. S., Kent, T. A., \& Felthous, A. R. (1997). Neuropsychological and cognitive psychophysiological substrates of impulsive aggression. Biological Psychiatry, 41, 1045-1061.

Bartholow, B. D., Bushman, B. J., \& Sestir, M. A. (2006). Chronic violent video game exposure and desensitization to violence: Behavioral and event-related brain potential data. Journal of Experimental Social Psychology, 42, 532-539. http://dx. doi.org/ 10.1016/j.jesp.2005.08.006

Bond, A. J., \& Surguy, S. M. (2000). Relationship between attitudinal hostility and P300 latencies. Progress in $\begin{array}{lllll}\text { Neuro-Psychopharmacology and Biological Pychiatry, 24, 1277-1288. } & \text {. }\end{array}$ http://dx.doi.org/10.1016/S0278-5846(00)00143-3 
Crocker, J., \& Major, B. (1989). Social stigma and self-esteem: The self-protective propertiesof stigma. Psychological Review, 96, 608-630. http://dx.doi.org/10.1037/0033-295x.96.4.608

Chen, A. T., Weng, X. C., Yuan, J. J., Lei, X., Qiu, J., Yao, D. Z., \& Li, H. (2008). The temporal features of self-referential processing evoked by chinese handwriting. Journal of Cognitive Neuroscience, 20, 816-827. http://dx.doi.org/10.1162/jocn.2 008.20505

Carretie, L., Mercado, F., Tapia, M., \& Hinojosa, J. A. (2001). Emotion, attention, and the "negativity bias", studied through event-related potentials. International Journal of Psychophysiol, 41, 75-85. http://dx.doi.org/10.1016/S0167-8760(00)00 195-1

Dodge, K. A., Pettit, J. E., \& Bates, J. E. (1994) Socialization mediators of the relation between socioeconomic status and child conduct problems. Child Development, 65, 649-665. http://dx.doi.org/ 10.1111/j.1467-8624.1994.tb00774.x

Dong, G., Yang, L., Hu, Y., \& Jiang, Y. (2009). Is N2 associated with successful suppression of behavior responses in impulse control processes? NeuroReport, 20, 537-542. http://dx.doi.org/10.1111/j.1469-8986.1994.tb02447.x

Doosje, B., Spears, R., \& Ellemers, N. (2002). Social identity as both cause and effect: The development of group identification in response to anticipated and actual changes in the intergroup status hierarchy. British Journal of Social Psychology, 41, 57-76. http://dx.doi.org/10.1348/014466602165054

Duncan, C. C., Rumsey, J. M., Wilkness, S. M., Denckla, M. B., Hamburger, S. D., \& Odou-Potkin, M. (1994). Developmental dyslexia and attention dysfunction in adults: brain potential indices of information processing. Psychophysiology, 31, 386-401. http://dx.doi.org/10.1111/j.1469-8986.1994.tb02447.x

Engelhardt, C. R., Bartholow, B. D., Kerr, G. T., \& Bushman, B. J. (2011). This is your brain on violent video games: Neural desensitization to violence predicts increased aggression following violent video game exposure. Journal of Experimental Social Psychology, 47, 1033-1036. http://dx.doi.org/10.1016/j.jesp.2 011.03.027

Gallo, L. C., \& Matthews, C. A. (2003). Understanding the association between socioeconomic status and physical health: Do negative emotions play a role? Psychological Bulletin, 129, 10-51. http://dx.doi.org/10.1037/0033-2909.129.1.10

Gerstle, J. E., Mathias, C. W., \& Stanford, M. S. (1998). Auditory P300 and self-reported impulsive aggression. Progress in Neuro-Psychopharmacol and Biological Psychiatry, 22, 575-583. http://dx.doi.org/10.1016/S0278-5846(98)002 7-X

Gilligan, J. (1996). Violence: Our deadly epidemic and its causes. New York, NY: Grosset Putnam.

Goodman, E., Adler, N. E., Kawachi, I., Frazier, A. L., Huang, B., \& Colditz, G. A. (2001). Adolescents' perceptions of social status: Development and evaluation of a new indicator. Pediatrics, 108, 1-8.

Hall, N. R., \& Crisp, R. J. (2008). Assimilation and contrast to group primes: The moderating role of ingroup identification. Journal of Experimental Social Psychology, 44, 344-353. http://dx.doi.org/10.1016/j.jesp.2007.07.007

Henry, P. J. (2009). Low-Status Compensation: A theory for understanding the role of status in cultures of honor. Journal of Personality and Social Psychology, 97, 451-466. http://dx.doi.org/10.1037/a0015476

Houston, R. J., \& Stanford, M. S. (2001). Mid-latency evoked potentials in self-reported impulsive aggression. International Journal of Psychophysiology, 40, 1-15. http://dx.doi.org/10.1016/S0167-8760(00)00120-3

Johnson, Jr. R. (1993). On the neural generators of the P300 component of the event-related potential. Psychophysiology, 30, 90-97.

Kraus, M. W., Piff, P. K., \& Keltner, D. (2009). Social class, sense of control, and social explanation. Journal of Personality and Social Psychology, 97, 992-1004.

Krämer, U. M., Büttner, S., Roth, G., \& Münte, T. F. (2008). Trait Aggressiveness modulates neurophysiological correlates of laboratory-induced reactive aggression in humans. Journal of Cognitive Neuroscience, 20, 1464-1477. http://dx.doi.org/10.1162/jocn.2008.20103.0

Lynch, J., \& Kaplan, G. (2000). Socioeconomic position. New York, NY: Oxford University.

Lynch, J. W., Kaplan, G. A., \& Salonen, J. T. (1997). Why do poor people behave poorly? Variation inadult health behaviours and psychosocial characteristics by stages of the socioeconomic lifecourse. Social 
Science \& Medicine, 44, 809-819. http://dx.doi.org/10.1136/jech.57.6.440

Lang, P. J., Bradley, M. M., \& Cuthbert, B. N. (2001). International affective picture system (IAPS): Instruction manual and affective ratings. Technical Report A-5. The Center for Research in Psychophysiology, University of Florida.

Li, H., Yuan, J. J., \& Lin, C. D. (2008). The neural mechanism underlying the female advantage in identifying negative emotions: An event-related potential study. NeuroImage, 40, 1921-1929. $\mathrm{http}: / / \mathrm{dx}$. doi.org/10.1016/j.jpsychires

Marmot, M., Bobak, M., \& Smith, D. G. (1995). Explanations for social inequalities in health. In: Amick III B, Levine S, Tarov AR, Walsh D, editors. Society and health. New York: Oxford University Press.

Mathias, C. W., \& Stanford, M. S. (1999). P300 under standard and surprise conditions in self-reported impulsive aggression. Neuro-Psychopharmacology and Biological Psychiatry, 23, 1037-1051. http://dx.doi.org/10.1016/S0278-5846(99) 00053-6

McFarlin, S. K., Fals-Stewart, W., Major, D. A., \& Justice, E. M. (2001). Alcohol use and workplace aggression: an examination of perpetration and victimization. Journal of Substance Abuse, 13, 303-21. http://dx.doi.org/10.1016/S0899-3289(0 1)00080-3

Miller, He. I. (1941). The frustration and aggression hypothesis. Psychological Review, 48, 337-342.

Perdeci, Z., Gulsun, M., Celik, C., Erdem, M., Ozdemir, B., Ozdag, F., \& Kilic, S. (2010). Aggression and the event-related potentials in antisocial personality disorder. Bulletin of Clinical Psychopharmacology, 20, 300-306.

Qiu, J., Zhang, Q. L., Li, H., Luo, Y. J., Yin, Q. G., Chen, A. T., \& Yuan, H. (2007). The event-related potential effects of cognitive conflict in a Chinese character-generation task. NeuroReport, 18, 881-886. http://dx.doi.org/10.1097/WNR. 0b013e3280d9e896

Ranchor, A. V., Bouma, J., \& Sanderman, R. (1996). Vulnerability and social class: Differential patterns of personality and social support over the social classes. Personality and Individual Differences, 20, 229-237.

Scherwitz, L., Perkins, L., Chesney, M., \& Hughes, G. (1991). Cook-Medley Hostility Scale and subsets: Relationship to demographic and psychosocial characteristics in young adults in the CARDIA study. Psychosomatic Medicine, 53, 36-49.

Stewart, J. L., Silton, R. L., Sass, S. M., Fisher, J. E., Edgar, J. C., Heller, W., \& Miller, G. A. (2010). Attentional bias to negative emotion as a function of approach and withdrawal anger styles: An ERP investigation. International Journal of Psychophysiology, 76, 9-18. http://dx.doi.org/10.1016/j.ijpsycho.2010.01.008

Smith, E. R., Seger, C. R., \& Mackie, D. M. (2007). Can emotions be truly group level? Evidence regarding four conceptual criteria. Journal of Personality and Social Psychology, 93, 431-446. http://dx.doi.org/10.1037/0022-3514.93.3.431

Tajfel, H., \& Turner, J. C. (1979). An integrative theory of intergroup conflict. In: Austin WG, Worchel S. editors. The social psychology of intergroup relations (pp. 33-47). Monterey, CA: Brooks/Cole.

Twenge, J. M., Baumeister, R. F., Tice, D. M., \& Stucke, T. S. (2001). If you can't join them, beat them: effects of social exclusion on aggressive behavior. Journal of Personality and Social Psychology, 81, 1058-1069. http://dx.doi.org/10.1037//0 022-3514.81.6.1058

Weenig, M. W. H., van der Salm, C. A., \& Wilke, H. A. M. (2004). The relationship between perceived in-group variability, number of contacts, and identification. Journal of Applied Social Psychology, 34, 872-886. http://dx.doi.org/10.1111/j.15 59-1816.2004.tb02575.x

Wolpe, J. (1982). The practice of behavior therapy. New York, NY: Pergamon.

Ybarra, O., Chan, E., \& Park, D. C. (2001). Young and old adults' concerns with morality and competence. Motivation and Emotion, 25, 85-100. http://dx.doi.org/ 10.1023/A: 1010633908298

Yuan, J. J., He, Y. Y., Zhang, Q. L., Chen, A. T., \& Li, H. (2008). Gender differences in behavioral inhibitory control: ERP evidence from a two-choice oddball task. Psychophysiology, 45, 986-993. http://dx.doi.org/10.111/j.1469-8986.2008.00639. 